\title{
COMPETITIVIDAD Y PERCEPCIÓN DEL SERVICIO TURÍSTICO PERUANO ESTUDIO DE INVESTIGACIÓN 2005
}

José Domingo Begazo Villanueva*

\begin{abstract}
RESUMEN
Los peruanos debemos buscar la riqueza dentro de nosotros mismos. Estamos llenos de oportunidades por todas partes, esperando por alguien que le de el valor y la fuerza necesaria para convertirla en algo atractivo y poderoso para vender al mundo.

La clave está en entender que somos una nación con una gran cultura viva fruto de siglos de mestizaje; justamente ese mestizaje ha hecho que nuestra cocina tenga una propuesta variada y diversa que ha cautivado al público internacional, y que es en ese mestizaje donde los peruanos deben encontrar la fuente de inspiración no solo para generar riqueza sino, sobretodo, para aceptarnos y querernos como nación. Recién a partir de esto podemos encontrar en nuestro interior todas aquellas ideas que luego saldrán transformadas en productos y en marcas para conquistar el planeta.
\end{abstract}

Palabras clave: Demanda turística, oferta turística, mercado turístico, marketing turístico, marketing mix turístico, marketing integrado, macromarketing turístico, micromarketing turístico, percepción, recurso turístico, satisfacción, turista.

\begin{abstract}
Peruvians should look for the wealth inside themselves. We, Peruvians, are full of opportunities, waiting for somebody to give value and the necessary force to transform it into something attractive and powerful to be sold in the world.

The key is to understand that we are a nation with a great living culture fruit of centuries of racial mestizaje ; exactly that mestizaje has made our kitchen have a varied and diverse proposals that have captured the international public, and it is in that mestizaje where Peruvians should find not only the source of inspiration to generate wealth but to accept and love themselves as a nation.
\end{abstract}

Keywords: Tourist demand, tourist supply, tourist market, tourist marketing, tourist marketing mix, integrated marketing, macro tourist marketing, micro tourist marketing, perception, tourist resource, satisfaction, tourist.

* Doctor en Administración. Magíster en Administración y en Desarrollo Económico Social. Profesor Principal e Investigador Permanente de la Facultad de Ciencias Económicas (UNMSM). Profesor de Post Grado de diversas Universidades y Centros Superiores de Enseñanza. 


\section{SITUACIÓN DEL TURISMO EN EL PERÚ}

Desde 1993 ha empezado a incrementarse el número de llegadas de visitantes al país, quienes deben enfrentar una infraestructura e instalaciones turísticas insuficientes para mantener el futuro crecimiento.

El Perú cuenta con una pobre red de caminos que incrementa el costo del viaje. Del total de carreteras $(78,034 \mathrm{Km}$.), las pavimentadas cubren solo un $13 \%(10,050 \mathrm{Km}$.); el resto se reparte de la siguiente manera: $18,535 \mathrm{Km}$. de carreteras afirmadas, $13,848 \mathrm{Km}$. de carreteras sin afirmar y 35,600 Km. de trochas carrozables.

Un aspecto que es crucial para el transporte aéreo son las condiciones en las que se encuentran la infraestructura de los aeropuertos del país. Actualmente el Perú cuenta con un total de 31 aeropuertos administrados por la Corporación Peruana de Aeropuertos Comerciales (CORPAC), de los cuales el $98 \%$ del tráfico internacional es absorbido por el aeropuerto de Lima.

Aún en los aeropuertos ubicados en las principales ciudades turísticas (Lima, Cusco, Iquitos y Arequipa) se tienen grandes limitaciones como ausencia de facilidades para arribos nocturnos, que empeoran con el clima y el incremento del número de vuelos.

En el sector público y privado y en la población local existe un insuficiente conocimiento de los temas ambientales, las leyes y las regulaciones. También hay insuficientes instituciones legales para la conservación ambiental del sector turístico y para el desarrollo turístico. Existe un insuficiente control y administración de los recursos naturales, en particular, en áreas naturales protegidas.

En la administración turística existen tan solo dos organizaciones relacionadas con el turismo. Usualmente las políticas se encuentran bajo la jurisdicción del Ministerio de Comercio Exterior y Turismo (MINCETUR) y la promoción está bajo la responsabilidad de PROMPERÚ. Actualmente la cooperación en el ámbito nacional para el desarrollo del turismo puede ser muy difícil entre las autoridades vinculadas con él. En tanto el turismo tenga relaciones con casi todas las industrias, es necesario que exista una estrecha cooperación entre ellas.

A pesar de su potencial turístico, algunas regiones no se han establecido como sitios turísticos debido a la ausencia de promoción. Nadie duda del potencial del Perú para el turismo debido a la cantidad de recursos culturales y naturales con que contamos, pero nuestros recursos no están siendo aprovechados adecuadamente por lo que es necesario superar muchas barreras para lograr el desarrollo de la industria.

Se calcula que el turismo en el Perú ha generado alrededor de 460,440 empleos entre directos e indirectos, lo que equivale al $4,4 \%$ de la población económicamente activa. De ese total, 121,548 empleos son generados directamente del sector turismo, que se desagrega de la siguiente manera: el $71.07 \%$ representa el rubro restaurantes (86,384 empleos), $18.63 \%$ se concentra en el rubro hospedaje (22,646 empleos), $4.05 \%$ representa las agencias de viajes $(4,918$ empleos) y otros rubros agrupan a 7,600 empleos que representan un $6.25 \%$.

El empleo indirecto ha generado 338,892 puestos de trabajo. Además, el sector turismo representa un aporte del orden del 4\% del Producto Bruto Interno (PBI). Comparándolo con otros sectores productivos, el PBI del sector turismo es relativamente bajo. Por ejemplo el sector agropecuario participa con el $9 \%$ del PBI nacional, el sector manufactura con un $15 \%$, el sector minería con un 6\%, el sector construcción con un $5 \%$, el comercio con $14 \%$, siendo el más alto el sector servicios (sin contar con el sector turismo) con un $36 \%$, y el más bajo el sector pesca con $1 \%$.

La realidad del Perú requiere de una labor de planificación estatal, pues aún no se ha logrado la madurez necesaria para dejar que el sector se desarrolle por sí solo en función del mercado. Tenemos un potencial similar al de otros países latinoamericanos como México, Costa Rica, Santo Domingo o Colombia, que han logrado cierto éxito gracias al impulso estatal. La pobre participación del Perú dentro del contexto mundial frente a las posibilidades que la industria ofrece debe obligar al planteamiento de objetivos claves cuyo cumplimiento permita adquirir competitividad. El Perú todavía no es visto como un destino turístico bien conocido. Gran parte de los extranjeros no han sido informados de la diversidad de nuestro patrimonio natural y arqueológico, y esto se deriva de la insuficiente presencia de nuestro país en la prensa y las noticias de los medios masivos extranjeros, así como de 
la insuficiencia de otras actividades promocionales. Muchos de los extranjeros ven en Perú a un país inseguro porque las noticias que llegan al exterior son mayormente acerca de terrorismo y desastres naturales.

Aún hay muchos destinos con potencial, pero se requiere de una orientación e impulso que el sector privado no puede asumir en las actuales circunstancias, pues el turismo peruano gira principalmente en torno a Machu Picchu (70\% del turismo). Otros destinos -como el lago Titicaca, el Colca y la región amazónica- aún no descubren su verdadero potencial, mientras que Chan Chan y el Callejón de Huaylas no cuentan para el turismo receptivo, y mucho menos para el interno debido a soporte de infraestructura pública, además de la escasa participación de los gobiernos locales en el desarrollo del turismo, a diferencia de lo que ocurre en otras realidades.

Dos razones principales hacen necesaria la adopción de un proceso de planificación: el desarrollo del turismo depende de decisiones del sector público (gobierno central o local) y privado (inversiones), y es necesario emprender acciones multisectoriales (cultura, seguridad, transporte, medio ambiente, etcétera). Al respecto cabe recordar la experiencia de España y Francia (región Languedoc-Roussillon). El objetivo político del turismo debe centrarse en la idea de "desarrollo y autorrealización local".

Es necesario trazar los lineamientos generales para que cada región o localidad pueda desarrollar sus propios planes de desarrollo turístico. La Agencia de Cooperación Internacional de Japón elaboró el Plan Maestro de Desarrollo Turístico Nacional para la República del Perú que ha definido y establecido prioridades para el desarrollo de nuevos destinos turísticos. El error es haber centralizado en el MINCETUR su ejecución, en lugar de orientar su realización a través de cada región.

Numerosos ministros y viceministros de Turismo han desfilado llenos de entusiasmo por el MINCETUR, pero en la práctica se involucraron con una actividad extremadamente compleja y para manejar esto es necesario contar con poder político y poder de decisión, que escaparon a su ámbito de acción.

Así mismo, la priorización requiere de estrategias de largo plazo y para ello se requiere que el poder político le confiera prioridad al tema; lamentablemente el turismo en el Perú sigue caótico y desarticulado, y seguirá así mientras no existan decisiones políticas de priorizarlo.

No debe extrañar entonces que en el Perú, empezando por los gobernantes, vivamos de espaldas al turismo por improvisación, voluntarismo o ignorancia, pese a que existe un marco guía y regulador que es el "Plan Maestro de Desarrollo Turístico Nacional en la República del Perú”, vigente desde el segundo semestre de 1999; por lo tanto no tenemos una visión real de cuanto sucede con el turismo en el resto de la "aldea global". El hecho de que nuestros vecinos estén captando más turismo receptivo no significa necesariamente que estemos formando mal a nuestros ejecutivos de turismo, sino que nuestros vecinos los están formando mejor.

\section{INTRODUCCIÓN}

El turismo en el Perú es una actividad con gran futuro, con un potencial muy grande y con una biodiversidad maravillosa: de los 114 ecosistemas en el mundo, el Perú tiene 84 y de los 32 climas, tiene 28. Además habría que tomar en cuenta el rico patrimonio histórico-cultural existente desde la época pre-inca. Por tal motivo, el Perú debería convertirse en líder de los países turísticos, si se tiene en cuenta que existen naciones con menos recursos turísticos, sin embargo tienen un mayor número de turistas que los visitan.

Los técnicos internacionales consideran al Perú entre los seis países con mayor producto turístico disponible, junto con México, España, Francia, Italia y Egipto, y se podrían desarrollar diversos tipos de turismo como el de aventura, esotérico, de salud, ecológico, arqueológico, termal, gastronómico, etc.

Por lo mencionado anteriormente, el sector turismo en nuestro país tiende a una constante expansión, pero ésta requiere de ciertos estándares de exigencia tanto en el trato, recibimiento, atención y conservación del cliente objetivo, por lo cual es necesario crear las condiciones e infraestructura necesarias para que dicho sector funcione como una actividad económica rentable, cumpliendo con las Normas Internacionales de Calidad ISO, además de contar con personal altamente preparado.

Si bien es cierto que recién estamos tratando de crear una imagen positiva del país en el 
extranjero, mientras que la población local no tenga una clara conciencia de la importancia del arribo de turistas al país, el incremento del turismo no va a ser significativo.

El tema ha sido de interés para diversos investigadores. Existe una diversidad de estudios sobre el turismo peruano pero éstos han sido realizados de manera aislada, vale decir enfocándolos de manera parcial y, en consecuencia, planteando soluciones parciales. Entre los más destacados tenemos el realizado por la Consultora Cheechi \& Company en 1965, cuya conclusión más importante fue que el Perú no está preparado para acomodar a un gran número de turistas exitosamente. También tenemos el realizado por Monitor Company con el auspicio de PROMPERÚ y el entonces MITINCI, hoy MINCETUR. Este estudio se inició en 1994 como parte del Proyecto Nacional "Construyendo las Ventajas Competitivas del Perú”, cuyo propósito era contribuir a que las empresas y ejecutivos peruanos comprendan las razones históricas que han llevado al crecimiento esporádico del turismo peruano, además de promover el desarrollo de una política turística coherente.

\section{DISEÑO EXPERIMENTAL}

El diseño del presente trabajo es descriptivo correlacional, esto es, se pretende explicar la relación de las variables que son objeto de investigación.

La población de esta investigación está dividida en dos grupos: el primer grupo lo conforman los turistas extranjeros arribados al Perú en julio del 2005, y el segundo grupo está compuesto por todas las empresas de servicios turísticos ubicadas en Lima, registradas al año 2004, que suman 11,425 empresas $(8,540$ restaurantes, 800 agencias de viajes, 2,025 establecimientos de hospedaje y 60 empresas de transporte terrestre).

\section{MARCO TEÓRICO}

La industria turística ha permitido el desarrollo económico y la modernización de muchos países debido a su capacidad para generar empleo, ingresos y divisas y por su gran contribución a la descentralización. Estos países han encontrado en el turismo un importante soporte para su desarrollo. Además de ello, frente a las crisis que se presentan, el turismo ha mostrado una capacidad de resistencia: sus tasas de crecimiento son superiores al promedio de otras industrias. Ello se debe a que la recesión económica interna del país de destino no afecta al turismo receptivo, basado en la atención a turistas extranjeros que inyectan divisas y ponen en marcha, gracias a su consumo, el desarrollo de las distintas actividades económicas.

Esta situación ha dado lugar a:

- La diversificación de la oferta turística por el desarrollo de actividades productivas de servicios o por la "puesta en valor" de nuevos atractivos turísticos.

- La ampliación progresiva de la demanda turística por el crecimiento masivo de los "flujos turísticos" a nivel mundial.

- Los desequilibrios estacionales entre la oferta y la demanda turística; y,

- El crecimiento agresivo de la competitividad, dentro de un mercado extremadamente dinámico.

En este sentido el estudio, conocimientos y aplicación del marketing, resultan instrumentos indispensables en el sector turístico para orientar el análisis de la demanda turística potencial o efectiva, y de la oferta turística que no solo debe adecuarse a las exigencias propias de la demanda, sino que también debe ofrecer nuevas y diversas posibilidades de selección.

Teniendo en cuenta lo dicho en el párrafo precedente es pues absolutamente necesario, en el estudio y posterior aplicación del Marketing Turístico, contar con el pleno conocimiento de los elementos e instrumentos de indagación y de decisiones que entran en una función de dirección, no solamente por su absoluta y necesaria aplicación sino también porque el objeto del Marketing Turístico es el de encontrar soluciones y alternativas, como se ha indicado anteriormente, teniendo presente que en este sector se encontrarán elementos no controlables que pueden y de hecho, condicionan la comercialización del producto turístico.

\section{MARKETING TURÍSTICO}

Según Aníbal Baca:

"El marketing turístico es la adopción sistemática y coordinada de la política de la empresa turística y de la política turística privada o estatal sobre un plan regional, 
nacional o internacional para una satisfacción óptima de los deseos y necesidades de determinados grupos de consumidores, obteniéndose una ganancia adecuada"'.

En esta definición se han tenido presentes las particularidades y características del producto y del mercado turístico, esto es la oferta y la demanda, elementos que requieren coordinación de las actividades empresariales para hacer el esfuerzo de acercar el producto al consumidor potencial.

Teniendo en cuenta los elementos considerados en la anterior definición y agregando referencias sobre los niveles de decisión y técnicas de aplicación, el Dr. Luciano Merlo define Marketing Turístico como

“...el conjunto de valoraciones y decisiones que sobre la base de un análisis continuo de las tendencias y disponibilidades de la demanda turística, se propone alcanzar las condiciones óptimas de formación de la oferta turística (producto turístico) y de su colocación en el mercado (demanda turística), mediante una constante coordinación de las iniciativas de las empresas privadas con las acciones de los poderes públicos" ${ }^{2}$.

Consideramos que es una definición más coherente y completa en el sentido de que armoniza la totalidad de elementos que constituyen el verdadero Marketing Turístico.

\section{PLANTEAMIENTO DE HIPÓTESIS}

\section{Hipótesis general}

Las características de los servicios turísticos, las estrategias de mercadeo y la percepción de los usuarios y su satisfacción guardan una relación escasa.

\section{Hipótesis específicas}

- Los servicios turísticos ofertados por las empresas tienen características generalizadas, centralistas y multisectoriales.

- Las estrategias de mercadeo practicadas por las empresas turísticas peruanas para promocionar y vender sus servicios son Extensión del Mercado Turístico, Diversificación Turística Concéntrica, y Desarrollo del Producto Turístico.
- La percepción de los usuarios de los servicios turísticos está referida a la carencia de modernidad y formalidad.

- La satisfacción de los usuarios de los servicios turísticos es de nivel regular.

\section{MÉTODOS}

Para el siguiente estudio se determinaron dos grupos a encuestar. El primero, conformado por los turistas extranjeros que arribaron al Perú en julio del 2005; y el segundo, las empresas de servicios turísticos registrados en Lima durante el año 2004.

De acuerdo a los grupos, cada uno tiene su propia muestra, las cuales se sumaron y totalizaron generando la muestra general de la investigación. Cada entrevista y encuesta tiene por finalidad afirmar o negar la hipótesis general y específicas.

La técnica de recolección de datos utilizada fueron el análisis documental utilizándose los archivos y registros del Ministerio de Comercio Exterior y Turismo (MINCETUR), PROMPERÚ y de la empresa Apoyo Consultores S.A., realizadas en el periodo 2004 mediante encuestas y entrevistas.

Para la reafirmación o negación de las percepciones y satisfacciones de los turistas con respecto a los servicios turísticos en el Perú se utilizaron los siguientes instrumentos de recolección de la información: cuestionarios estructurados y guías de entrevista.

Después de hacer una evaluación y críticas de los datos e información a fin de garantizar la veracidad y confiabilidad, se organizaron y procesaron, construyendo tablas de frecuencias unidimensionales y bidimensionales. A partir de ellas se construyeron cuadros estadísticos, cálculo de estadígrafos y medidas de posición, dispersión y asociación para facilitar el análisis e interpretación de los datos y resultados, así como las pruebas estadísticas de hipótesis.

\section{ANÁLISIS Y DISCUSIÓN}

Es importante considerar los siguientes temas para su análisis y discusión que pueden ser origen de investigaciones futuras:

- Dar prioridad al desarrollo de la Región Turística Norte, más que a las otras dos regio- 
nes. La Región Turística Sur cuenta con muchos de los centros / recursos turísticos bien conocidos en el mundo, tales como Cusco, Machu Picchu, Líneas de Nazca, Puno, Lago Titicaca, etc. La inversión también se ha inducido a la región atrayendo a muchos turistas. Por otra parte, la Región Turística Norte está todavía en una etapa prematura en términos de desarrollo turístico a pesar de que cuenta con diversos y valiosos recursos turísticos. La región tiene menores beneficios derivados de la actividad turística, sector que podría contribuir al desarrollo de la región, especialmente en áreas remotas y económicamente frágiles.

- Impulsar a los gobiernos locales y apoyarlos para establecer una Corporación de Desarrollo Turístico Regional (CDTR) como una política de descentralización. El CDTR debería convertirse en un órgano de desarrollo y operación responsable del desarrollo de la región.

- Establecer un plan para reforzar la promoción turística, especialmente en los mercados no analizados.

- En relación con la promoción turística, deben realizarse continuamente diversas investigaciones de mercado y almacenar y analizar la información para el establecimiento de nuevas estrategias de promoción y comercialización.

- Esforzarse por mantener las condiciones de seguridad y publicitar esas condiciones del país entre países europeos, para eliminar la mala imagen del Perú entre los turistas.

- Establecer medidas para impulsar la participación de la población local en la industria turística, tales como un sistema de certificación en el ecoturismo; un sistema de administración de los parques arqueológicos nacionales; un sistema de certificación de los guías locales, etc.

- Mejorar las instalaciones en cada lugar turístico ofreciendo fácil acceso y diversos servicios como centros de información; señalización y/o simbología adecuada; tableros explicativos; restaurantes; instalaciones sanitarias, etc. El desarrollo de las amenidades al costado de las carreteras son esenciales para apoyar a los turistas que se encuentran viajando por tierra en el circuito y el corredor turístico.

\section{CONCLUSIONES}

Concluida el estudio de investigación podemos enunciar las siguientes conclusiones:

1. Limitado número de destinos turísticos, especialmente para los visitantes internacionales, ya que la mayoría de ellos solo visitan Lima, Nazca, Cusco, y Machu Picchu. Es importante establecer medidas para distribuir a los visitantes a los sitios turísticos del norte.

2. Baja tasa de ocupación en los establecimientos de alojamiento. En Lima la proporción de alojamiento de lujo (4 y 5 estrellas) es cercana al 50\%; en el Perú, en su conjunto, es del $32.3 \%$.

3. Carencia de alojamiento en categorías superiores. Todavía no se han establecido claramente categorías de alojamiento por regiones y clases. La inversión en alojamiento se concentra mayormente en Lima y se puede observar una carencia de inversión en sitios turísticos en todo el país. A excepción de Lima, es notable la ausencia de hoteles de 4 y 5 estrellas.

4. Responsabilidades de conservación. El Instituto Nacional de Cultura (INC), las municipalidades y los gobiernos regionales tienen responsabilidades en la conservación del patrimonio cultural. Sin embargo, sus recursos presupuestales son insuficientes para cumplir con tales responsabilidades.

5. Necesidad de coordinación. Actualmente la cooperación en el ámbito nacional para el desarrollo del turismo puede ser difícil entre las autoridades vinculadas con él. En tanto el turismo tiene relaciones con casi todas las industrias, es inevitable la cooperación en muchas áreas como por ejemplo la construcción de infraestructura, el proceso en los aeropuertos, la preservación ambiental y la vida silvestre, el desarrollo y la capacitación de recursos humanos, las políticas de cambio de divisas y la importación de productos agrícolas, etc. Para realizar esa cooperación el área turística debe tener una cierta organización que permita la coordinación y la integración, concentrándose cada uno de los esfuerzos para el desarrollo turístico en los diferentes campos relacionados. 
6. Fortalecimiento de asociaciones. En las principales ciudades con atractivos turísticos la asociación de la industria turística está organizada según representantes de hoteles, agencias y guías, etc. Estas asociaciones generalmente no son operativas, y algunas veces son solo nominales.

7. Deficiente coordinación en la promoción. En lugar de PROMPERÚ, son las embajadas peruanas en el exterior las que deberían estar encargadas de las actividades turísticas promocionales. Sin embargo, las actuales actividades promocionales no siguen las políticas establecidas por el propio PROMPERÚ o por el MINCETUR y dependen de la habilidad y el entusiasmo del personal de cada embajada. Es por esta razón que, en general, las actividades promocionales que realizan las embajadas no tiene un efecto apreciable.

8. Ausencia de actividades de promoción para el turismo receptivo. Todavía no ha sido identificado el principal mercado para el turismo receptivo en base al cual se deberían enfocar las actividades promocionales. Esto debe solucionarse a través de encuestas más detalladas y la identificación de las tendencias y los potenciales de cada país.

9. Establecimiento de atractivos en el turismo peruano. No han sido claramente definidos los puntos de venta de Perú. Esto debería solucionarse con el análisis de los recursos y características del turismo de nuestro país, comparándolas con los países vecinos y competidores.

10. Carencia de materiales promocionales. Los materiales de promoción que satisfagan las necesidades de los turistas de interés especial todavía no se encuentran disponibles. Con el objeto de practicar una promoción más meticulosa se necesitan materiales promocionales para cada tema.

11. Deficiente presentación e interpretación. Es necesario afirmar que uno de los más importantes atractivos del Perú es su historia y su arqueología, esto es, las ruinas de las culturas pre-Inca e Inca. Por lo tanto, los principales museos regionales y las cédulas de interpretación en el sitio de las ruinas son esenciales para que los turistas aprecien totalmente el patrimonio cultural.
12. Deficientes instalaciones para el transporte terrestre. En todo el país se carece de señalización de tráfico vehicular para el uso turístico. Es necesario preparar esta señalización que permita atender las necesidades de los visitantes que se dirigen a los sitios arqueológicos.

13. Desarrollo de telecomunicaciones. Debe promoverse la expansión de la red de líneas telefónicas, aprovechando la vitalidad del sector privado.

14. Importancia de la policía turística y de la policía municipal. La efectiva utilización de la policía turística y de la policía municipal forma parte importante en la estrategia de turismo. Su reforzamiento debe ser cuidadosamente considerado con su disposición presupuestal y sus efectos recíprocos. La utilización de la policía municipal debe considerarse como una alternativa del reforzamiento de la policía turística.

15. Carencia de información en los sitios turísticos. A excepción de Cusco, prácticamente no existe ningún otro centro turístico accesible con la suficiente información. Aunque algunos gobiernos regionales tiene oficinas de información, en la práctica no pueden ser aprovechados por los turistas.

\section{NOTAS}

1. Baca Astete, Aníbal. Marketing Turístico. 1995. P. 41.

2. Merlo, Luciano. Introducción al Estudio del Marketing Turístico. 1990. Pág. 32.

\section{BIBLIOGRAFÍA}

Acerenza Delgado, Miguel A. (1984). Administración del Turismo: Conceptualización y Organización. México, Editorial Trillas.

Acerenza Delgado, Miguel A. (1985) Administración del Turismo: Planificación y Dirección. México, Editorial Trillas.

Acerenza Delgado, Miguel A. (1993). Promoción Turística: Un Enfoque Metodológico. México, Editorial Trillas.

Agencia de Cooperación Internacional del Japón y Ministerio de Industria, Turismo, Integración y Negociaciones Comerciales Internacionales (MITINCI). (1999). Plan Maestro de Desarrollo Turístico Nacional en la República del Perú (fase-1). Lima. 
Altés Machín, Carmen. (1995). Marketing y Turismo: Introducción al Marketing de Empresas y Destinos Turísticos. Ed. Síntesis.

Baca Astete, Aníbal. (1995). Marketing Turístico. Lima, H.F. Impresores.

Banco Mundial (BM), Cooperación Andina de Fomento (CAF), Banco Interamericano de Desarrollo (BID), Programa de las Naciones Unidas para el Desarrollo (PNUD). (2001). Carta de Navegación para el Gobierno Peruano.

Begazo Villanueva, José Domingo. (1999). Propuestas para la Formación del Ejecutivo en Turismo en una Economía Globalizada. Tesis para optar el Grado Académico de Doctor en Administración. UIGDLV. Octubre.

Chechi And Company. (1965). Posibilidades del Turismo en el Perú. Washington DC, Organización de Estados Americanos (OEA).

Editorial Reparaz. (1998). Guía del Perú. Lima, Editorial Reparaz.

Hatton, Angela. (2000). La Guía definitiva del Plan de Marketing. Prentice Hall.

Heighes Thiessen, Enrique y Brent Ritchie J.R. (1981). Marco Conceptual en el que se basa la Formulación del Plan Maestro Nacional para Desarrollar el Turismo en el Perú. Lima, ESAN - Departamento de Investigación.

Iglesias Millán, Joseph. (2001). Técnicas de Investigación aplicadas al Sector Turístico. Ed. Síntesis.

INDECOPI. (2000). Situación y Perspectivas del Mercado Aerocomercial Peruano. INDECOPI - Área de Estudios Económicos. Documento de Trabajo $N^{\circ}$ 012-2000. En: Diario El Peruano, Normas Legales. Setiembre.

Kotler, Philip. (1997). Mercadotecnia para Hotelería y Turismo. México, Ed. Prentice Hall Hispanoamericana SA.

López, Antonio. (1992). Manual de Marketing General y de los Servicios Turísticos. Editorial Síntesis.
Lundberg, Donald E. (1986). Organización y Administración del Turismo. Barcelona, Edic. Centrium Técnicas y Científicas.

Mcintosh; Goeldner; Ritchie. (1999). Turismo, Planeación, Administración y Perspectivas. Segunda Edición. Editorial Limusa.

Ministerio de Industria, Turismo e Integración (MITINCI). (1983). Producto Turístico Peruano: Tipología y Presentación. Lima, Fondo de Promoción Turística.

Monitor Company. (1994). Construyendo las Ventajas Competitivas del Perú. El Turismo. Lima.

Muñoz Oñate, Fernando. (1997) Marketing Turístico. Madrid, Ed. Centro de Estudios Ramón Areces SA.

PROMPERÚ. (1998). El Rol de PROMPERÚ en el Turismo: Estrategias y Acciones.

PROMPERÚ. (2001). Nivel de Satisfacción del Turista Extranjero 2001. Lima.

PROMPERÚ. (2001). Perfil del Turista extranjero 2001. Lima.

Ramirez Cavassa, César. (1993). Gestión Administrativa para Empresas Turísticas. México, Edit. Trillas.

Rufin Moreno, Ramón. (2002). Las Empresas Turísticas en la Sociedad de la Información. Centro de Estudios Ramón Areces.

Santesmases Mestre, Miguel. (1999). Marketing. Conceptos y Estrategias. Cuarta Edición. Madrid, Ediciones Pirámide.

Schluter Regina, Jonás. (2000). Investigación en Turismo y Hotelería. Turísticas. Librerías.

Universidad San Martín de Porres. (1997). Investigaciones en Turismo. Lima, Facultad de Turismo y Hotelería. Año I Volumen I.

Vásquez, Rodolfo. (1998). Marketing: estrategias y aplicaciones sectoriales. Civitas.

Villena Lescano, Carlos. (1993). Introducción al Turismo: Teoría y Realidad Peruana. Tercera Edición. Lima. 